\title{
The Design and Implementation of Fly Back Type High Frequency Switching Power Supply Based on OB2201
}

\author{
LIU Xia ${ }^{1, a}$ \\ ${ }^{1}$ School of Physics and Mechatronics Engineering , Xi'an University, Xi'an 710065,China \\ aliuxia126@126.com
}

Keywords: High Frequency Switching Power Supply; OB2201; Fly Back Type

\begin{abstract}
Switching power supply is on the basis of the development of modern electronic science and technology, using the power switch tube, by controlling the switching time (duty cycle) to make the output voltage stability of the high frequency power supply, it includes two parts of the main circuit and PWM control circuit. The working frequency of switch power supply is higher, making its conversion efficiency is higher, the highest can reach more than $90 \%$, also can greatly reduce the volume of power supply, can save material, finally makes the power supply cabinet and delicate, improve the utilization rate of electric energy and protecting the environment is of great significance.
\end{abstract}

\section{Introduction}

Power electronic era of rapid development, as the electronic equipment power plays a key role of the heart, especially the delegate of direction of regulated power supply development, switching power supply with high efficiency and energy saving. By input protection circuit, switch power supply EMI, rectifier, filter circuit, high frequency transformer, output rectifier filter circuit, control circuit and so on, is the input AC voltage into a DC output voltage of AC/DC converter [1]. At present, the switching power supply to meet the demands of the development of modern electronic equipment mainly to develop in the direction of intelligent, high frequency, miniaturization, etc., has become the optimization of small and medium-sized power electronics products. With the rapid development of power electronics technology, power electronic devices and is closely related to people's work and life, intelligent application will greatly promote the development of the fly back type high frequency switching power supply market [2].

In this paper, based on the analysis of power supply related data at home and abroad research, the switching power supply design. First of all, the topology of the switching power supply is studied, and the fly back type topology structure are analyzed in detail; Secondly, according to the trend of the development of the power supply of current control mode are analyzed and studied. Then to the design of transformer is analyzed, especially in the selection of parameters and the transformer winding aspects has carried on the key research; Finally combining the above analysis, the power supply the hardware circuit structures, and has carried on the calculation to the related data sets.

\section{The basic principle of switch power supply}

With the rapid development of power electronics technology, power electronic devices and is closely related to people's work and life, and the electronic equipment is inseparable from the reliable power supply, into the $80 \mathrm{~s}$ is made up of the computer power supply switch power supply, power generation, the first complete computer into the switch power supply in the $90 \mathrm{~s}$ have entered various electronic, electrical equipment, program-controlled switches, communications, electronic test equipment such as power supply, control equipment power supply has been widely used for switching power supply, promote the rapid development of the technology of switching power supply. It is short for a switching power supply, switch power supply, often referred to as the input AC voltage into a DC output voltage of AC/DC converter. The main circuit of switch power supply of electromagnetic interference (EMI) filter, the input rectifier filter circuit, the power conversion 
circuit, PWM control circuit, the output rectifier filter circuit, as shown in figure 1 [3-4]. Auxiliary circuit has input over-voltage protection circuit, output overvoltage protection circuit, over-current protection circuit, etc.

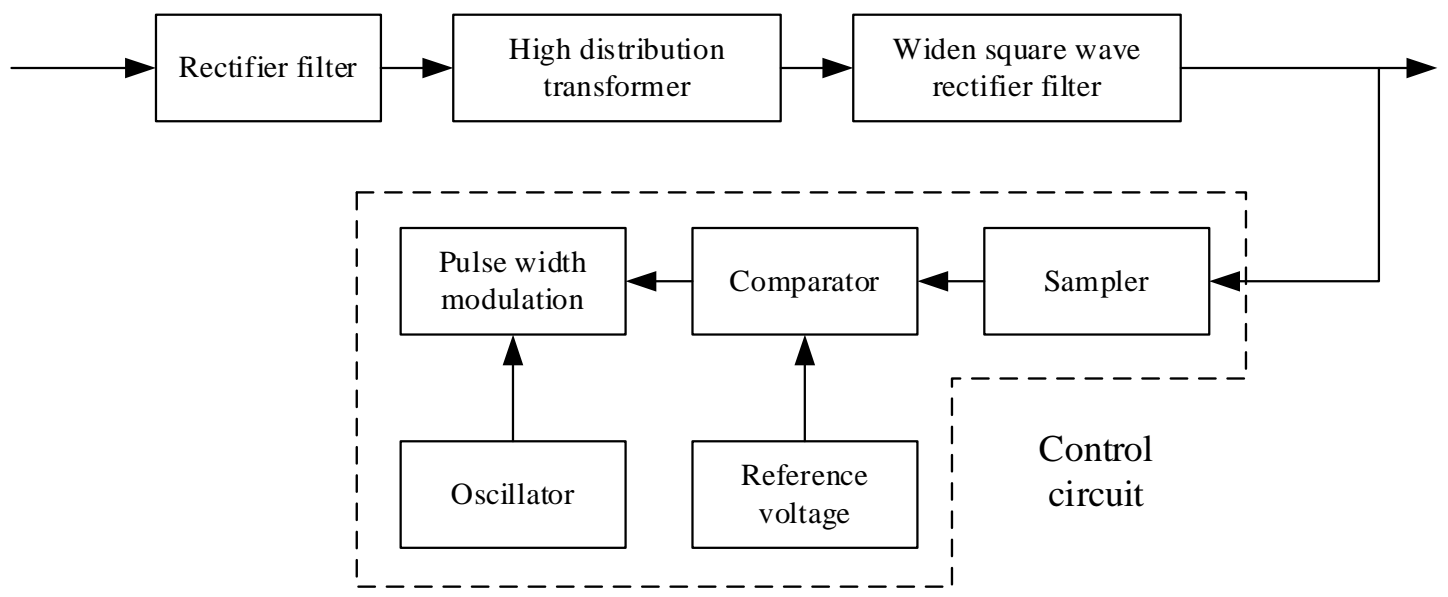

Figure 1. The basic circuit of switching power supply block diagram

The working process of the switch power supply is quite easy to understand, in the linear power supply, make power transistor in the linear model, and the linear power supply, PWM switching power supply is to get the power transistor in the state of the conduction and shut off. Compared with the linear power supply, PWM switching power supply is through more effective working process. Chopper, namely the input dc voltage chop into amplitude is equal to the input voltage amplitude of the pulse voltage.

\section{Fly back type high frequency switching power supply control circuit design based on OB2201}

High frequency switching power supply control path contains a controller, a feedback circuit and auxiliary power supply of three parts, this paper design the power supply is adopted by the PWM control mode, so to use pulse width controller to complete control of the power switch tube, through to the output pulse width adjustment to realize voltage regulator. This article chose OB2201 as control chip, the chip it to adopt the current control mode, mainly used in the fly back type topology circuits. OB2201 built-in error amplifier, current comparator, owe voltage comparator and so on, the main advantages are: the input over-voltage protection, output over current protection, owe voltage locking, overheating protection, overload protection. The highest working frequency of up to $90 \mathrm{KHZ}$, the maximum input voltage of 28V [5]. OB2201 feedback and current feedback power to adjust the duty ratio, OB2201 constitute a typical circuit diagram of switch power supply.

$220 \mathrm{v}$ alternating current (ac) after VC, capacitor C1 rectifier bridge rectifier filter, after resistor R1 step-down to OB2201 VCC (6 feet), to provide chip OB2201 open voltage, when the chips after start-up, the bias of transformer by the rectifier VD2 rectifier, capacitor C2 rectifier filter for chip OB2201 after normal working voltage, (R2 for partial pressure resistance in this picture, the function is used to adjust the rectifier VD2 rectifier, capacitor C2 rectifier dc voltage, after filtering for the normal work of the chip provide appropriate voltage) at the same time by the resistance R3 and R4 after partial pressure on error amplifier inverting the 2 feet, and provide feedback for chip OB2201 voltage, to control the duty ratio of drive pulse, to achieve the goal of the rated output voltage. Pin 1 external resistor R7 to control oscillation frequency, maximum oscillation frequency of $90 \mathrm{KHZ}$. The pins 5 work output pulse signal to drive the MOS tube, the original edge transformer N1 N2 energy to the negative side of the winding, the rectifier filter tubes VD3, capacitance $\mathrm{C}$ after rectifying filtering, the output dc voltage of load. MOS tube at the bottom of the RS for current sampling resistance, resistance to resistance RS sampling current 0 b2201 into chip pins 3 formed the current feedback loop. The chip OB220i for the double loop control system of power supply, power supply stability is very high. 


\section{The main switch power supply circuit design}

Switching power supply is the use of modern power electronic technology, control switch tube opened and shut off time ratio, to maintain stable output voltage of a power supply, switching power supply by general pulse width modulation (PWM) control IC and MOSFET. With the development of power electronic technology and innovation to make switching power supply technology is also in constant innovation. Currently, switching power supply with the characteristics of small, lightweight and high efficiency are widely used almost all electronic devices, is the rapid development of electronic information industry indispensable to a way of power supply. High frequency is its development direction, high frequency, the miniaturization of switch power supply, and make the switch power supply into a wider range of application fields, especially in the field of high and new technology application, promoted the high-tech products of miniaturization, light change. In addition the development and application of switch power supply in security monitoring, saving energy, saving resources and protecting the environment is of great importance.

The main circuit of high frequency switch power supply is to convert alternating current to direct current output of the entire process, basically has the following several parts, as shown in figure 2 .

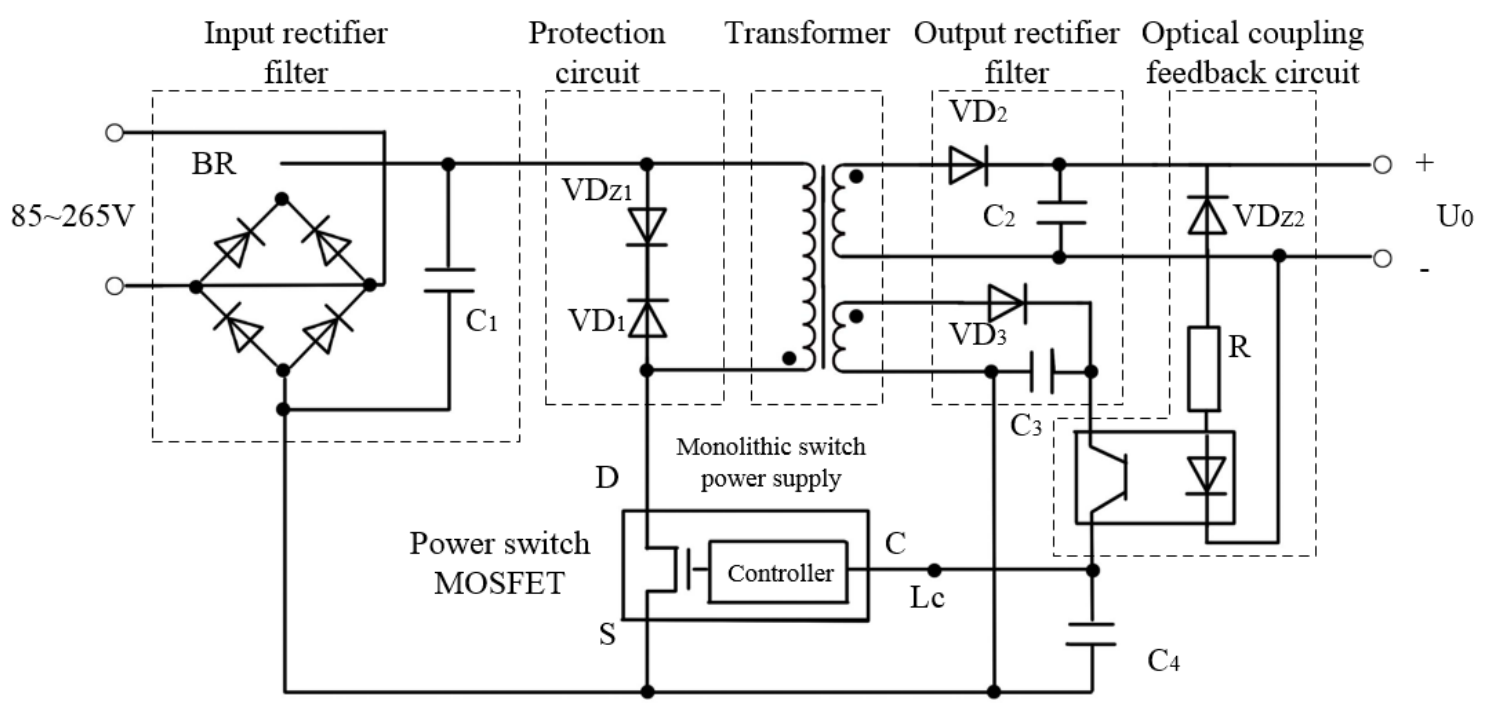

Figure 2. The main circuit of high frequency switch power supply

The input filter circuit to prevent introduction of interference from the power supply into line, the inhibition of electronic equipment to produce noise conduction out at the same time. Rectifier circuit rectifier circuit is convert alternating current into a single direction of direct current (dc). Switching circuit through the controller to the control of power tube made after rectifying circuit rectifier dc converted into high frequency alternating current (ac). Power transformer is used to implement the transformation. The output rectifier filter circuit is stable and reliable high frequency square wave can be converted to direct current (dc).

\section{Conclusion}

With the rapid development of science and technology and the progress of the society, low loss, high power, high reliability, green environmental protection gradually become the main development direction of switching power supply. This paper through to the high frequency switching power supply is studied and analyzed, and successfully designs a fly back switch power supply based on OB2201, by testing the power of each index has reached the design requirements. This article has made certain achievements, but needs to be studied further. Such as: surge current research, electromagnetic compatibility, is designed in this paper, due to the lack of experiment 
equipment and theory, to do more research; PCB design because of the lack of a lot of experience there is big problem.

\section{Acknowledgements}

The Project of Xi'an Science and technology plans (CX12189WL11)

\section{Reference}

[1] Gacio, David, et al. "A universal-input single-stag2e high-power-factor power supply for HB-LEDs based on integrated buck-flyback converter." Industrial Electronics, IEEE Transactions on 58.2 (2011): 589-599.

[2] Singh, Bhim, et al. "Comprehensive study of single-phase AC-DC power factor corrected converters with high-frequency isolation." Industrial Informatics, IEEE Transactions on 7.4 (2011): 540-556.

[3] Liu, Jun, et al. "LCC resonant converter operating under discontinuous resonant current mode in high voltage, high power and high frequency applications." Applied Power Electronics Conference and Exposition, 2009. APEC 2009. Twenty-Fourth Annual IEEE. IEEE, 2009.

[4] Alonso, J. Marcos, et al. "Analysis and design of the integrated double buck-boost converter as a high-power-factor driver for power-LED lamps." Industrial Electronics, IEEE Transactions on 59.4 (2012): 1689-1697.

[5] Kwon, Jung-Min, and Bong-Hwan Kwon. "High step-up active-clamp converter with input-current doubler and output-voltage doubler for fuel cell power systems." Power Electronics, IEEE Transactions on 24.1 (2009): 108-115. 